\title{
Clinical outcomes of single implant supported crowns versus 3-unit implant-supported fixed dental prostheses in Dubai Health Authority: a retrospective study
}

Sara Hussain Alhammadi ${ }^{1}$, Girvan Burnside ${ }^{2}$ (D) and Alexander Milosevic ${ }^{1 *}$ (D)

\begin{abstract}
Background: This study assessed retrospectively the clinical outcomes of single implant-supported crowns and implant-supported fixed dental prostheses (FDPs).

Methods: This case series compared biological and technical complications in single implant-supported crowns and implant-supported bridges in a time framed sample of all patients who received dental implants between 2009 and 2016 in Dubai Health Authority. Only 3-unit implant-supported prostheses (FDPs) with one intervening pontic and an implant each end were included for comparison to single crown supported implants. Cantilevered implants, implantsupported dentures and cases involving bone grafts or sinus lifts were excluded. The primary outcome measure was marginal bone loss, measured on digital radiographs taken after prosthesis placement at baseline and one year after implant loading, whilst peri-implantitis and technical complications were secondary outcomes. Mixed regression models adjusted for clustering of implants within patients was used for patient and implant factor associations.

Results: A total of 454 patients (152 males; 302 females) had 1673 implants. The mean age of males (53.7 years, SD 14.6) was significantly greater than females ( 49.3 years, SD 12.9, $\mathrm{p}<0.001)$. Mean mesial bone loss on the FDPs was significantly greater at 1 year $(1.14 \mathrm{~mm}, \mathrm{SD} 0.63)$ compared with the mesial surface of single implant-supported crowns $(0.30 \mathrm{~mm}, \mathrm{SD} 0.43, \mathrm{p}<0.001)$. Mean distal bone loss was also significantly greater at 1 year on the distal surfaces of implants supporting bridgework (1.29 mm, SD 0.71) compared with distal surfaces on single implant-supported crowns $(0.36 \mathrm{~mm}$, SD 0.54, $\mathrm{p}<0.001)$. Mean marginal bone loss mesially and distally around implants placed in the lower anterior sextant was significantly greater compared to all other sites $(p<0.001)$. Bone loss by gender, patient's age and medical condition was not different between the 2 implant groups. Screw loosening was the main technical complication (11.5\%) whilst peri-implantitis occurred rarely (0.5\%). The 66 cement retained implants had significantly more complications compared to the 1607 screw retained implants $(p<0.001)$.
\end{abstract}

Conclusions: Mean marginal bone loss around the supporting implants of FDPs (3-unit fixed bridgework) was greater than on single implant-supported crowns at one year after implant loading. Position in the mouth was associated with bone loss. Biological and technical complications occurred rarely.

Keywords: Dental implants, Bone loss, Technical complications

\footnotetext{
*Correspondence: alex.milosevic@outlook.com

${ }^{1}$ Hamdan Bin Mohamed College of Dental Medicine, Mohamed Bin

Rashid University of Medicine and Health Sciences (MBRU), Dubai, UAE

Full list of author information is available at the end of the article
}

(c) The Author(s) 2021. Open Access This article is licensed under a Creative Commons Attribution 4.0 International License, which permits use, sharing, adaptation, distribution and reproduction in any medium or format, as long as you give appropriate credit to the original author(s) and the source, provide a link to the Creative Commons licence, and indicate if changes were made. The images or other third party material in this article are included in the article's Creative Commons licence, unless indicated otherwise in a credit line to the material. If material is not included in the article's Creative Commons licence and your intended use is not permitted by statutory regulation or exceeds the permitted use, you will need to obtain permission directly from the copyright holder. To view a copy of this licence, visit http://creativecommons.org/licenses/by/4.0/. The Creative Commons Public Domain Dedication waiver (http://creativeco mmons.org/publicdomain/zero/1.0/) applies to the data made available in this article, unless otherwise stated in a credit line to the data. 


\section{Background}

The survival and/or complications of single implant-supported crowns have been compared to implant-supported bridges (fixed dental prostheses) and reviewed systematically [1]. The survival of single implant-supported crowns over 5 and 10 -years was reported to be $94.5 \%$ and $89.4 \%$ respectively, which was greater than implant-supported prostheses at 10-years (86.7\%) [1]. Studies have compared biological and prosthetic complications of implantsupported crowns with tooth supported prostheses but few studies have compared single implant-supported crowns with the 3-unit fixed-fixed implant-supported bridge or FDP (fixed dental prosthesis). Pooled success rates at 5 years for implant-supported single crowns was higher at $95 \%$ compared to natural tooth supported FDPs at $84 \%$ (95\% CI $79-89 \%$ ) [2]. Furthermore, the estimated cumulative survival and complications of posterior 3-unit FDPs were not different at 15 years when compared with posterior implant-supported crowns but anterior implant-supported crowns survived significantly better [3]. A recent systematic review and meta-analysis concluded that implant-supported 3-unit FDPs had survival rates no different to those of tooth-supported 3-unit FDPs [4]. Only one study has directly compared 3 adjacent single implant-supported crowns (non-splinted), 3 adjacent splinted (connected) implant-supported crowns and 3-unit implant-supported FDPs with one intervening pontic [5]. The non-splinted and splinted crowns had worse survival than 3-unit FDPs, termed implantsupported bridges in the study [5]. Prosthodontic complications and peri-implantitis were the lowest in the FDP group with a significant three-fold increased risk of implant related complications in the 3 adjacent nonsplinted single implant crowns compared to implantsupported bridges [5]. Splinted implants were reported to have improved load distribution and reduced marginal bone loss using finite element analysis and photoelastic modelling $[6,7]$. The rationale for splinting has been questioned in light of recent developments in dental implant design, implant surface properties and improved surgical techniques [8-10].

Plaque accumulation can lead to calculus formation, peri-mucositis or peri-implantitis with subsequent bone loss around the implants [11]. The primary advantage of a single implant-supported crown is ease of effective interproximal hygiene, better passivity of the framework and ease of removal or repair compared to splinted or connected units [9].

Forces transferred to implants are concentrated in the coronal 2 to $3 \mathrm{~mm}$ of crestal bone surrounding an implant [12]. Additionally, overloading may produce micro-fractures of crestal bone, mechanical failure and fracture of the implant or fatigue fractures of the prosthetic components [13]. The mandible has been shown to deform between $420 \mu \mathrm{m}$ and $1.06 \mathrm{~mm}$ during function $[14,15]$. Thus, restoration with single crown supported implants may minimize screw loosening or fractures as a result of mandibular flexion [16], whilst a fixed-fixed design may reduce stress concentration at the crestal bone margin resulting in better bone stability. Furthermore, fabrication of a passive fit of the connected prosthetic super-structure on implants is technically more difficult to achieve than is the case with individual implant-supported crowns [6].

The estimated survival of 2116 implant-supported fixed partial dentures after $6-7$ years for the 10 studies in a meta-analysis was $93.6 \%$ and $97.5 \%$ for single implants [17]. A 10-year randomized controlled trial assessed marginal bone around multiple adjacent dental implants restored with connected and single prostheses found a mean $1.2 \mathrm{~mm}$ marginal bone loss around connected dental implants compared to a mean $1.3 \mathrm{~mm}$ marginal bone loss around single dental implants, but the $0.1 \mathrm{~mm}$ difference was not considered clinically significant [7]. Others have reported no significant difference in bone loss around single and connected dental implants or that connected implants showed greater crestal bone loss of $0.2 \mathrm{~mm}$ compared to single implants $[4,18]$.

A 10-Year retrospective study compared the prosthetic complications in single implant-supported crowns to fixed-fixed implant-supported bridges and found that fixed-fixed implant-supported bridges had more technical complications compared to single implants [19]. A quarter had prosthetic complications, of which chipped ceramic was the most frequent followed by screw loosening and de-cementation [19]. Others found that $38.7 \%$ of fixed-fixed implant-supported bridges had complications after 5 years [1].

The lack of literature regarding the clinical outcomes of implants placed in Dubai prompted this investigation which aimed to assess and compare the clinical outcomes of single implant-supported crowns to 3-unit fixed-fixed implant-supported bridges placed in Al Badaa Dental Centre in Dubai Health Authority (DHA) between January 2009 and December 2016. The primary outcome measure was crestal bone height and complications such as implantitis, mobility, screw loosening and decementation were secondary outcomes. This study asks the question, 'Is bone loss in 3-unit implant-supported dental prostheses (FDPs) with one intervening pontic different to single implant-supported crowns one year after prosthesis placement/loading? A secondary aim was to determine'What factors influence clinical outcomes in implant-supported bridges (FDPs) and implant-supported single crowns?' 


\section{Methods}

The study was a retrospective descriptive study of a time framed implant case series. All consecutive cases of a single implant-supported crown or a 3-unit implantsupported prosthesis (FDP/bridge) with an implant at each end and one intervening pontic placed in the anterior and/or posterior region were included. As treatment was non-randomised and the study used secondary data from one clinic in DHA, which was pooled, individual consent for the study was not required, although all patients consented to the treatment. The study was approved by the Dubai Research Ethics Committee (Ref: DSREC-SR-03/2018_04).

Data was collected from patients' electronic records in Dubai Health Authority (DHA) using the D4W dental practice management software (Dental4Windows, Centaur Ltd, Australia). The anonymised patient demographic data included gender, age, medical history, patients' smoking habits and number of remaining teeth excluding the third molars. To be included, all implant prostheses had to be in function for at least 1 year. Cantilevered implants, implants supporting complete or removal partial dentures and any implant site that received bone graft material or a sinus lift procedure were excluded. Patients on bisphosphonate therapy or who had bone disease were excluded but patients with any other medical condition were included. Implant information regarding implant manufacturer, position, dimensions, time of insertion, time of loading, age of the implant and type of anchorage were entered into the database. Case type was dichotomised into single implant crown or implant-supported dental prosthesis (FDP). Biological complications included bone height mesially and distally, periapical radiolucency, implant mobility, peri-implantitis, and implant removal. Prosthetic complications included screw loosening, screw fracture, ceramic chipping, de-cementation of implant crown and any re-make of the prosthesis. Implants 'In function' in this study were defined as an implant and prostheses in situ regardless of the presence or absence of biological or technical complications.

Crestal bone height was measured on standardised peri-apical digital radiographs using Digora software. To minimise measurement error all radiographs were taken with the long cone parallel technique with a Rinn ORA positioner (Dentsply Sirona, Charlotte, NC 28277) a source to skin distance of $200 \mathrm{~mm}$ (8 inches) and a Planmeca ProSensor ${ }^{\circledR} \mathrm{HD}$ intra-oral digital sensor (Planmeca Oy, FI-00880 Helsinki, Finland) placed in a Rinn XCP DS Fit (Dentsply Sirona) universal sensor positioner whilst the patient was biting into the bite block. Mesial and distal bone height was measured from the implant abutment interface to the most apical area of bone implant contact by one examiner (SAH) who was not involved in the patient's treatment. For the FDP cases, the mesial and the distal aspects of each implant were measured. The first radiograph was taken at the time of prosthetic placement as a baseline measurement and the second radiograph was taken at least one-year post prosthesis fitting but no more than 18 months post-placement. Ten randomly selected baseline radiographs had bone height measurements performed twice, at least two weeks apart, in order to determine the reliability of this measurement and calculate an Intra-examiner Correlation Co-efficient (ICC). Standard oral and implant hygiene instructions such as flossing and interdental brushing were given to all patients who were requested to attend for annual follow-up.

Statistical analysis was performed using SAS software (version 9.4; SAS Institute, Cary, NC, USA). The associations of outcomes with patient and implant level factors were assessed using mixed regression models, adjusting for the clustering of implants within patients. Mixed linear regression models were used for crestal bone loss, and mixed logistic regression models for complications. Univariable models were fitted for each factor, and also multivariable models including all patient and implant level factors.

\section{Results}

The Intraclass Correlation Coefficient (ICC) was 0.84 which is considered good. A total of 454 cases $(66 \%$ female and $34 \%$ male) met the inclusion criteria with 1673 implants having been placed. Table 1 shows that males had a mean age of 54.0 years compared to 49.0 years for females. The mean number of teeth present in the mouth of females was 24.0 and for males this was 23.3.

The characteristics of the included cases are shown in Table 2. Mean implant age, defined in this study as the time from implant placement until the time of data collection was 4.9 years and the mean time from implant insertion to prosthesis placement/loading was 8.8 months. The first bone height radiographic measurement was at prosthesis placement and all second bone readings were taken one year after prosthesis placement. Mean age of single implants (4.8 years, SD 2.2) was similar to implants supporting a FDP (5.0 years, SD 2.3).

Table 1 Age of the participants by gender

\begin{tabular}{llll}
\hline Gender & N & Mean & Std. deviation \\
\hline Age & & & \\
Females & 302 & 49.0 & 12.9 \\
Males & 152 & 54.0 & 14.6 \\
\hline
\end{tabular}


Table 2 Characteristics of the cases included in the study

\begin{tabular}{lll}
\hline Characteristics & Frequency & Percent (\%) \\
\hline Medically fit & 291 & 64 \\
Medical condition present & 163 & 36 \\
Non-smoker & 396 & 87 \\
Smoker & 58 & 13
\end{tabular}

Implants were grouped into two categories as either single crown cases or FDP cases but it should be noted that 111 cases had a mixture of both single and implantsupported bridges (FDPs). The implant abutment interface connection was categorised into screw or cement and four different implant manufacturers were used by the operators who placed the implants (Table 3).

The most frequent sites for implant placement were the lower left and right posterior sextants while the least common site was the lower anterior sextant (Table 4).

Tables 5 and 6 shows mean mesial and distal crestal bone loss according to several study variables, and results from both unadjusted and adjusted regression analyses.

Bone height was measured on radiographs at baseline when the prosthesis was placed and 1-year after prosthesis placement. Adjusted analyses for bone loss by gender found no differences although in the unadjusted analysis, males had significantly greater mean crestal bone loss distally $(\mathrm{p}=0.048)$ but not mesially compared to females. Patient's age was divided into three groups as follows: young (20-40 years), middle (41-60 years), and older ( $>60$ years). Mean crestal bone loss mesially and distally increased with age but this was not significant in the adjusted analysis (Tables 5, 6). Mean crestal

Table 3 Implant and operator data

\begin{tabular}{lcl}
\hline & Frequency & Percent (\%) \\
\hline Case type by implant & & \\
$\quad$ Single & 780 & 46.6 \\
FDP & 893 & 53.4 \\
Implant-abutment connection & & \\
$\quad$ Screw type & 1607 & 96.1 \\
$\quad$ Cement type & 66 & 3.9 \\
Implant manufacturer & & \\
Astra & 51 & 3 \\
$\quad$ Xive & 485 & 29 \\
$\quad$ Ankylos & 1125 & 67.2 \\
$\quad$ Frialit & 12 & 0.7 \\
Operator by patient & & \\
$\quad$ Maxillofacial surgeons & 217 & 48 \\
Restorative (periodontist and pros- & 237 & 52 \\
$\quad$ thodontist) & & \\
\hline
\end{tabular}

Table 4 Position of implant in the oral cavity

\begin{tabular}{lcl}
\hline Implant position & Frequency & Percent (\%) \\
\hline Upper right posterior sextant & 347 & 20.7 \\
Upper anterior sextant & 176 & 10.5 \\
Upper left posterior sextant & 277 & 16.6 \\
Lower left posterior sextant & 389 & 23.3 \\
Lower anterior sextant & 92 & 5.5 \\
Lower right posterior sextant & 392 & 23.4 \\
Total & 1673 & 100 \\
\hline
\end{tabular}

bone loss in the FDP group was $1.13 \mathrm{~mm}$ mesially and $1.29 \mathrm{~mm}$ distally which was significantly greater than in the single implant-supported crown group.

After adjusting for all factors, mean mesial and distal crestal bone loss in patients with a medical condition was not significantly greater compared to medically fit patients (Tables 5, 6). There was no significant difference in mean mesial or distal crestal bone loss between smokers and non-smokers. (Table 5).

Implants placed in the lower anterior sextant, had significantly greater crestal bone loss mesially and distally compared to the other sextants in the unadjusted analysis, although the adjusted value for distal bone loss was not significant $(\mathrm{p}=0.065)$ (Tables 5,6$)$. Mean mesial crestal bone loss around Ankylos and Xive implants was greater than around Astra and Frialit but there was no difference distally. Cases treated by maxillofacial surgeons exhibited significantly greater crestal bone loss mesially and distally compared to restorative operators after adjusted analysis for all variables. Although there was little difference between maxillofacial surgeons and restorative operators in the unadjusted analysis, after adjusting for all other factors there was a statistically significantly higher bone loss in patients treated by restorative operators.

Of the 1673 implants, 83\% had no complication whereas only $17 \%$ had a complication. Furthermore, $96.1 \%$ of implants were still in function and $3.1 \%$ required remake of the prosthesis. Only $0.8 \%$ had to be removed as shown in Table 7.

Table 8 shows that significantly more complications occurred in the FDP group $(n=177)$ compared to the implant-supported crowns $(n=107)$. Patients with common medical conditions such as diabetes, hypertension and cardio-vascular disease did not have significantly more implant complications compared to fit and healthy patients (Table 8). Implant manufacturer and operator had no significant difference on implant complications in both adjusted and unadjusted analyses whilst implant position was only significant in the 
Table 5 Mean crestal bone loss (mesial) one year after placement by study variables

\begin{tabular}{|c|c|c|c|}
\hline $\begin{array}{l}\text { Study variables ( } \mathrm{pts}=\text { number of patients }{ }^{\mathrm{a}} \text {, } \\
\mathrm{n}=\text { number of implants) }\end{array}$ & $\begin{array}{l}\text { Mean crestal bone loss } \\
\text { mesially (SD) mm }\end{array}$ & Unadjusted $\beta(95 \% \mathrm{Cl})^{\mathrm{b}} \mathrm{p}$ value & Adjusted $\beta(95 \% \mathrm{Cl})^{\mathrm{C}} p$ value \\
\hline \multicolumn{4}{|l|}{ Gender } \\
\hline Male $(p t s=152, n=610)$ & $0.78(0.73)$ & Ref & Ref \\
\hline \multirow[t]{2}{*}{ Female $(p t s=302, n=1063)$} & $0.72(0.66)$ & $-0.06(-0.17,0.04)$ & $0.00(-0.09,0.09)$ \\
\hline & & $p=0.233$ & $p=0.963$ \\
\hline \multicolumn{4}{|l|}{ Age } \\
\hline $20-40(\mathrm{pts}=124, \mathrm{n}=332)$ & $0.63(0.72)$ & Ref & Ref \\
\hline $41-60(p t s=198, n=751)$ & $0.68(0.64)$ & $0.06(-0.06,0.18)$ & $-0.10(-0.19,0.00)$ \\
\hline \multirow[t]{2}{*}{$>60(p t s=132, n=590)$} & $0.89(0.70)$ & $0.26(0.13,0.39)$ & $-0.04(-0.15,0.07)$ \\
\hline & & $p<0.001$ & $p=0.104$ \\
\hline \multicolumn{4}{|l|}{ Case type } \\
\hline Single crown $(n=780)$ & $0.30(0.43)$ & Ref & Ref \\
\hline \multirow[t]{2}{*}{ FDP group $(n=893)$} & $1.13(0.63)$ & $0.86(0.80,0.92)$ & $0.86(0.81,0.92)$ \\
\hline & & $p<0.001$ & $p<0.001$ \\
\hline \multicolumn{4}{|l|}{ Medical condition } \\
\hline $\mathrm{No}(\mathrm{pts}=291, \mathrm{n}=1031)$ & $0.67(0.66)$ & Ref & Ref \\
\hline \multirow[t]{2}{*}{ Yes (pts $=163, n=642)$} & $0.86(0.71)$ & $0.17(0.07,0.27)$ & $0.07(-0.01,0.15)$ \\
\hline & & $p=0.001$ & $p=0.080$ \\
\hline \multicolumn{4}{|l|}{ Smoking } \\
\hline $\mathrm{No}(\mathrm{pts}=396, \mathrm{n}=1482)$ & $0.75(0.67)$ & Ref & Ref \\
\hline \multirow[t]{2}{*}{ Yes (pts $=58, n=191)$} & $0.68(0.79)$ & $-0.01(-0.16,0.14)$ & $0.00(-0.13,0.12)$ \\
\hline & & $p=0.905$ & $p=0.988$ \\
\hline \multicolumn{4}{|l|}{ Implant abutment connection } \\
\hline Screw $(n=1607)$ & $0.75(0.69)$ & Ref & Ref \\
\hline \multirow[t]{2}{*}{ Cement $(n=66)$} & $0.56(0.56)$ & $-0.14(-0.33,0.04)$ & $-0.06(-0.21,0.08)$ \\
\hline & & $p=0.128$ & $p=0.394$ \\
\hline \multicolumn{4}{|l|}{ Implant position (sextant) } \\
\hline UR posterior $(n=347)$ & $0.77(0.73)$ & Ref & Ref \\
\hline Upper anterior $(n=176)$ & $0.70(0.60)$ & $-0.10(-0.21,0.02)$ & $-0.15(-0.25,-0.05)$ \\
\hline UL posterior $(n=277)$ & $0.73(0.69)$ & $-0.01(-0.11,0.09)$ & $0.03(-0.05,0.11)$ \\
\hline LL posterior $(n=389)$ & $0.72(0.70)$ & $-0.08(-0.17,0.01)$ & $-0.01(-0.09,0.06)$ \\
\hline Lower anterior $(n=92)$ & $1.16(0.68)$ & $0.28(0.13,0.42)$ & $0.12(0.00,0.25)$ \\
\hline \multirow[t]{2}{*}{ LR posterior $(n=392)$} & $0.67(0.64)$ & $-0.08(-0.17,0.01)$ & $-0.01(-0.09,0.06)$ \\
\hline & & $p<0.001$ & $p=0.002$ \\
\hline \multicolumn{4}{|l|}{ Implant manufacturer } \\
\hline Ankylos $(n=1125)$ & $0.75(0.69)$ & Ref & Ref \\
\hline Astra $(n=51)$ & $0.46(0.50)$ & $-0.30(-0.51,-0.08)$ & $-0.30(-0.47,-0.13)$ \\
\hline Xive $(n=485)$ & $0.76(0.69)$ & $0.07(-0.03,0.17)$ & $0.04(-0.04,0.12)$ \\
\hline \multirow[t]{2}{*}{ Frialit $(n=12)$} & $0.58(0.63)$ & $-0.26(-0.67,0.15)$ & $-0.23(-0.56,0.09)$ \\
\hline & & $p=0.008$ & $p<0.001$ \\
\hline \multicolumn{4}{|l|}{ Operator } \\
\hline Maxillofacial $(p t s=217, n=854)$ & $0.78(0.70)$ & Ref & Ref \\
\hline \multirow[t]{2}{*}{ Restorative (pts $=237, \mathrm{n}=819$ ) } & $0.70(0.68)$ & $-0.02(-0.12,0.08)$ & $0.09(0.02,0.17)$ \\
\hline & & $p=0.666$ & $p=0.018$ \\
\hline
\end{tabular}

\footnotetext{
${ }^{a}$ Number of patients (pts) is only presented for patient level variables
}

${ }^{b}$ Estimates and confidence intervals derived from mixed linear regression models, implants clustered within patients

c Estimates and confidence intervals derived from mixed linear regression models, implants clustered within patients, adjusted for all other factors in the table 
Table 6 Mean crestal bone loss (distal) one year after placement by study variables

\begin{tabular}{|c|c|c|c|}
\hline $\begin{array}{l}\text { Study variables ( } p t s=\text { number of patients, } \\
n=\text { number of implants) }\end{array}$ & $\begin{array}{l}\text { Mean crestal bone loss distally } \\
\text { (SD) } \mathrm{mm}\end{array}$ & Unadjusted $\beta(95 \% \mathrm{Cl}) \mathrm{p}$ value ${ }^{b}$ & Adjusted $\beta(95 \%$ Cl) $p$ value \\
\hline \multicolumn{4}{|l|}{ Gender } \\
\hline Male $(p t s=152, n=610)$ & $0.93(0.85)$ & Ref & Ref \\
\hline \multirow[t]{2}{*}{ Female $(p t s=302, n=1063)$} & $0.82(0.75)$ & $-0.11(-0.23,-0.00)$ & $-0.08(-0.18,0.01)$ \\
\hline & & $p=0.048$ & $p=0.094$ \\
\hline \multicolumn{4}{|l|}{ Age } \\
\hline $20-40(\mathrm{pts}=124, \mathrm{n}=332)$ & $0.74(0.85)$ & Ref & Ref \\
\hline $41-60(p t s=198, n=751)$ & $0.80(0.77)$ & $0.08(-0.06,0.21)$ & $-0.10(-0.20,0.01)$ \\
\hline \multirow[t]{2}{*}{$>60(p t s=132, n=590)$} & $0.99(0.75)$ & $0.26(0.18,0.40)$ & $-0.09(-0.21,0.03)$ \\
\hline & & $p<0.001$ & $p=0.168$ \\
\hline \multicolumn{4}{|l|}{ Case type } \\
\hline Single crown $(n=780)$ & $0.36(0.54)$ & Ref & Ref \\
\hline \multirow[t]{2}{*}{ FDP group $(n=893)$} & $1.29(0.71)$ & $0.93(0.87,1.00)$ & $0.94(0.87,1.01)$ \\
\hline & & $p<0.001$ & $p<0.001$ \\
\hline \multicolumn{4}{|l|}{ Medical condition } \\
\hline $\mathrm{No}(\mathrm{pts}=291, \mathrm{n}=1031)$ & $0.78(0.77)$ & Ref & Ref \\
\hline \multirow[t]{2}{*}{ Yes (pts $=163, n=642)$} & $0.98(0.80)$ & $0.18(0.07,0.29)$ & $0.08(-0.01,0.17)$ \\
\hline & & $p=0.002$ & $p=0.071$ \\
\hline \multicolumn{4}{|l|}{ Smoking } \\
\hline $\mathrm{No}(\mathrm{pts}=396, \mathrm{n}=1482)$ & $0.87(0.78)$ & Ref & Ref \\
\hline \multirow[t]{2}{*}{ Yes (pts $=58, n=191)$} & $0.78(0.87)$ & $-0.03(-0.19,0.14)$ & $-0.08(-0.22,0.06)$ \\
\hline & & $p=0.728$ & $p=0.290$ \\
\hline \multicolumn{4}{|l|}{ Implant abutment connection } \\
\hline Screw $(n=1607)$ & $0.86(0.80)$ & Ref & Ref \\
\hline \multirow[t]{2}{*}{ Cement $(n=66)$} & $0.77(0.56)$ & $-0.03(-0.24,0.18)$ & $0.05(-0.23,0.12)$ \\
\hline & & $p=0.761$ & $p=0.542$ \\
\hline \multicolumn{4}{|l|}{ Implant position (sextant) } \\
\hline UR posterior $(n=347)$ & $0.91(0.84)$ & Ref & Ref \\
\hline Upper anterior $(n=176)$ & $0.87(0.67)$ & $-0.08(-0.22,0.05)$ & $-0.16(-0.28,-0.05)$ \\
\hline UL posterior $(n=277)$ & $0.83(0.78)$ & $-0.07(-0.19,0.04)$ & $-0.03(-0.12,0.07)$ \\
\hline LL posterior $(n=389)$ & $0.82(0.83)$ & $-0.06(-0.17,0.05)$ & $-0.06(-0.15,0.03)$ \\
\hline Lower anterior $(n=92)$ & $1.25(0.80)$ & $0.22(0.04,0.39)$ & $0.05(-0.10,0.20)$ \\
\hline \multirow[t]{2}{*}{ LR posterior $(n=392)$} & $0.76(0.73)$ & $-0.14(-0.24,0.03)$ & $-0.06(-0.15,0.03)$ \\
\hline & & $p=0.002$ & $p=0.065$ \\
\hline \multicolumn{4}{|l|}{ Implant manufacturer } \\
\hline Ankylos $(n=1125)$ & $0.67(0.51)$ & Ref & Ref \\
\hline Astra $(n=51)$ & $0.88(0.80)$ & $-0.15(-0.40,0.09)$ & $-0.16(-0.36,0.04)$ \\
\hline Xive $(n=485)$ & $0.86(0.79)$ & $0.08(-0.04,0.19)$ & $0.06(-0.03,0.15)$ \\
\hline \multirow[t]{2}{*}{ Frialit $(n=12)$} & $0.83(0.83)$ & $-0.10(-0.57,0.38)$ & $-0.06(-0.44,0.33)$ \\
\hline & & $p=0.256$ & $p=0.159$ \\
\hline \multicolumn{4}{|l|}{ Operator } \\
\hline Maxillofacial (pts $=217, n=854)$ & $0.89(0.78)$ & Ref & Ref \\
\hline \multirow[t]{2}{*}{ Restorative (pts $=237, \mathrm{n}=819$ ) } & $0.82(0.80)$ & $-0.02(-0.09,0.13)$ & $0.11(0.02,0.19)$ \\
\hline & & $p=0.729$ & $p=0.017$ \\
\hline
\end{tabular}

\footnotetext{
${ }^{a}$ Number of patients (pts) is only presented for patient level variables
}

${ }^{b}$ Estimates and confidence intervals derived from mixed linear regression models, implants clustered within patients

c Estimates and confidence intervals derived from mixed linear regression models, implants clustered within patients, adjusted for all other factors in the table 
Table 7 Distribution of implant complications and final outcomes

\begin{tabular}{lcl}
\hline & Frequency & Percent (\%) \\
\hline No complications & 1389 & 83 \\
$\begin{array}{l}\text { Complications } \\
\text { Implant mobility }\end{array}$ & 6 & \\
Peri-implantitis & 9 & 0.4 \\
Screw loosening & 193 & 0.5 \\
Screw fracture & 12 & 11.5 \\
Chipped ceramic & 19 & 0.7 \\
Crown de-cementation & 45 & 1.1 \\
Final outcome & & 2.7 \\
In function & 1608 & \\
Remake prostheses & 52 & 96.1 \\
Removal of implant & 13 & 3.1 \\
\hline
\end{tabular}

unadjusted analysis. Cement retained prostheses had significantly more than expected implant complications compared to screw retained prostheses (Table 8).

\section{Discussion}

The Emirate of Dubai had a total population of 2,976,455 in 2017 , of which $74.9 \%$ were males in the working age category of 20-50 years [20]. It is interesting to note that females accounted for $60 \%$ of the patients who received implant treatment in the dental centre in Dubai, despite the fact that all Emirati nationals are entitled to receive free implant treatment. Females are more proactive regarding oral health compared to males which would account for the higher number of females in the present study.

In the present study, biological complications were categorized as mesial and distal crestal bone loss one year after prosthesis placement, periapical radiolucency, implant mobility and implant removal. Prosthetic complications were screw loosening, screw fracture, ceramic chipping, de-cementation and re-make of the implant prosthesis.

Factors that could affect marginal bone included gender, age, medical condition, smoking, operator, implant manufacturer, implant anchorage, implant position and case type. Previously reported bone loss after 1 year in function averaged between 1.5 and $2 \mathrm{~mm}$ and thereafter annual bone loss was $0.2 \mathrm{~mm}$ [21]. In the present study, after a year in function, mean marginal bone loss around single implant supported crowns was $0.30 \mathrm{~mm}$ mesially and distally $0.36 \mathrm{~mm}$, whereas in the 3-unit implant supported prostheses (FDPs), mean marginal bone loss was $1.13 \mathrm{~mm}$ mesially and $1.29 \mathrm{~mm}$ distally. While both types of implant restoration had bone loss within the range reported by Albrektsson et al. [21], the implant supported prostheses had significantly more bone loss after one year. Although outcome measures differ, this conflicts with the results of Ravida et al. who found that patients with a 3-unit implant supported bridge had a $72 \%$ lower risk of developing peri-implantitis compared to 3 nonsplinted crowns next to each other and that survival of 3-unit implant supported bridges (FDPs) was better than both 3 adjacent single (non-splinted) implant-supported crowns and 3 splinted implant-supported crowns over the mean 76-month follow-up period [5].

In the systematic review conducted by Pol and coworkers, the annual failure rate of 3-unit tooth supported FDPs was higher at $3.6 \%$ than 3-unit implant supported FDPs (2.6\%) [4]. In this study, the greater bone loss at one year in 3-unit implant supported FDPs compared to single crowns is intuitive in so far as plaque control is more difficult under bridge pontics. To better understand this relationship, the bone height on the side of the implant adjacent to the pontic, which is more difficult to clean, should be assessed and compared to the side away from the pontic.

The results presented here found that implantsupported fixed prostheses have significantly greater mesial and distal marginal bone loss compared to single implant-supported prostheses. The reasons for this are not fully understood but inter-proximal hygiene is more difficult around implant-supported fixed prostheses [22, 23]. Although survival data is not presented here, our results are intuitive and indicate single implant-supported crowns are likely to have better survival, at least in the short term, compared to implant-supported FDPs because less bone is lost.

Although males had lost more bone distally compared to females, this was not significant in the adjusted analysis. Poor access for oral hygiene on the distal aspect of the implant, greater forces distally and greater bite force in males than in females $[24,25]$ may account for this. Also, the males in this study were significantly older than the females and it is well known that age influences crestal bone loss and, as visual acuity and manual dexterity decline, maintaining oral health becomes more difficult.

The medical conditions were gained from the hospital records and 163 patients in this study had either diabetes, hypertension and/or cardiovascular disease. None of the patients had neoplastic or metabolic bone disease. Contraindications to the placement of implants in medically compromised patients are relative rather than absolute. Implants are a feasible treatment option in almost any medically compromised patient, but excellent plaque control, regular maintenance and follow-up are required [26]. Even in patients with altered bone metabolism such as osteoporotic individuals, implant survival is comparable to those seen in healthy individuals $[27,28]$. The 
Table 8 Frequency of implant complications by study variables

\begin{tabular}{|c|c|c|c|c|}
\hline Study variables & No complication & Complication & Unadjusted odds ratio $(95 \% \mathrm{Cl})$ & $\begin{array}{l}\text { Adjusted odds ratio (95\% } \\
\text { Cl)* }\end{array}$ \\
\hline \multicolumn{5}{|l|}{ Gender } \\
\hline Male & $489(80 \%)$ & $121(20 \%)$ & Ref & Ref \\
\hline \multirow[t]{2}{*}{ Female } & $900(85 \%)$ & $163(15 \%)$ & $0.83(0.52,1.31)$ & $0.65(0.36,1.18)$ \\
\hline & & & $p=0.411$ & $p=0.159$ \\
\hline \multicolumn{5}{|l|}{ Age } \\
\hline $20-40$ & $277(83 \%)$ & $55(17 \%)$ & Ref & Ref \\
\hline $41-60$ & $620(83 \%)$ & $131(17 \%)$ & $1.10(0.63,1.94)$ & $0.93(0.50,1.73)$ \\
\hline \multirow[t]{2}{*}{$>60$} & $492(83 \%)$ & $98(17 \%)$ & $0.96(0.52,1.76)$ & $0.71(0.34,1.48)$ \\
\hline & & & $p=0.859$ & $P=0.616$ \\
\hline \multicolumn{5}{|l|}{ Case type } \\
\hline Single crown & $673(86 \%)$ & $107(14 \%)$ & Ref & Ref \\
\hline \multirow[t]{2}{*}{ FDP group } & $716(80 \%)$ & $177(20 \%)$ & $1.48(1.03,2.14)$ & $1.74(1.16,2.61)$ \\
\hline & & & $p=0.036$ & $p=0.008$ \\
\hline \multicolumn{5}{|l|}{ Medical condition } \\
\hline No & $873(85 \%)$ & $158(15 \%)$ & Ref & Ref \\
\hline \multirow[t]{2}{*}{ Yes } & $516(80 \%)$ & $126(20 \%)$ & $1.49(0.95,2.33)$ & $1.64(0.96,2.79)$ \\
\hline & & & $p=0.086$ & $p=0.071$ \\
\hline \multicolumn{5}{|l|}{ Smoking } \\
\hline No & $1222(82 \%)$ & $260(18 \%)$ & Ref & Ref \\
\hline \multirow[t]{2}{*}{ Yes } & $167(87 \%)$ & $24(13 \%)$ & $0.68(0.34,1.39)$ & $0.58(0.25,1.38)$ \\
\hline & & & $p=0.293$ & $p=0.220$ \\
\hline \multicolumn{5}{|c|}{ Implant abutment connection } \\
\hline Screw & $1369(85 \%)$ & $238(15 \%)$ & Ref & Ref \\
\hline \multirow[t]{2}{*}{ Cement } & $20(30 \%)$ & $46(70 \%)$ & $29.32(12.56,68.41)$ & $36.07(14.59,89.18)$ \\
\hline & & & $\mathrm{p}<0.001$ & $p<0.001$ \\
\hline \multicolumn{5}{|c|}{ Implant position (sextant) } \\
\hline UR posterior & $292(84 \%)$ & $55(16 \%)$ & Ref & Ref \\
\hline Upper anterior & $134(76 \%)$ & $42(24 \%)$ & $1.90(1.04,3.48)$ & $1.14(0.59,2.23)$ \\
\hline UL posterior & $232(84 \%)$ & $45(16 \%)$ & $0.87(0.52,1.48)$ & $0.79(0.45,1.37)$ \\
\hline LL posterior & $328(84 \%)$ & $61(16 \%$ & $1.16(0.70,1.91)$ & $1.14(0.68,1.93)$ \\
\hline Lower anterior & $83(90 \%)$ & $9(10 \%)$ & $0.59(0.23,1.48)$ & $0.34(0.12,1.00)$ \\
\hline \multirow[t]{2}{*}{ LR posterior } & $320(82 \%)$ & $72(18 \%)$ & $1.49(0.92,2.42)$ & $1.40(0.84,2.35)$ \\
\hline & & & $p=0.040$ & $p=0.084$ \\
\hline \multicolumn{5}{|c|}{ Implant manufacturer } \\
\hline Ankylos & $43(84 \%)$ & $8(16 \%)$ & Ref & Ref \\
\hline Astra & $418(86 \%)$ & $67(14 \%)$ & $0.86(0.31,2.44)$ & $0.84(0.26,2.70)$ \\
\hline Xive & $917(82 \%)$ & $208(18 \%)$ & $0.85(0.53,1.37)$ & $0.80(0.46,1.38)$ \\
\hline \multirow[t]{2}{*}{ Frialit } & $11(92 \%)$ & $1(8 \%)$ & $0.60(0.05,7.04)$ & $0.23(0.01,5.21)$ \\
\hline & & & $p=0.893$ & $p=0.695$ \\
\hline \multicolumn{5}{|l|}{ Operator } \\
\hline Maxillofacial & 703 (82\%) & $151(18 \%)$ & Ref & Ref \\
\hline \multirow[t]{2}{*}{ Restorative } & $686(84 \%)$ & $133(16 \%)$ & $1.03(0.67,1.61)$ & $1.39(0.82,2.35)$ \\
\hline & & & $p=0.883$ & $p=0.216$ \\
\hline
\end{tabular}

* Estimates and confidence intervals derived from mixed logistic regression models, adjusted for clustering of implants within patients

bidirectional relationship between diabetes and periodontal disease can increase the risk of peri-implantitis and impair osseointegration in poorly controlled cases but when diabetes is well controlled, implant survival is similar to healthy patients within the first 6 years, but survival reduces over 20 years [29]. In the present study 
after adjustment for all variables, medical conditions did not result in significantly greater crestal bone loss compared to healthy individuals. This supports implant provision in medically compromised patients. Diz and colleagues reviewed a range of medical problems and concluded that the degree of disease control may be far more important than the nature of the systemic disorder itself [30]. This confirms the previous finding that age, sex, ASA classification and immediate implants were not predictive for bone loss within the first year after implant placement [31]. The medication profile of this group of patients was not investigated but future research should study the association between medicines and implant outcome as medication such as glucocorticoids, nonsteroidal anti-inflammatories and chemotherapy can adversely affect wound healing [32].

Significant bone loss has been reported in heavy smokers (>15 cigarettes per day) after 4 years [33]. Conversely, Calvo-Guirado et al. [34] reported that smoking had no negative influence on crestal bone loss after a 5 year follow up. The effect of smoking on implant survival is still controversial but it is not a contraindication for implant therapy. The prevalence of smoking in the Middle East has increased, especially in young adults with the added influence of poly-tobacco use including midwakh/dokha and water pipes (shisha) [35-37]. In the present study, there was no significant difference on crestal bone between smokers and non-smokers. This can be explained by the low number of smokers although underreporting for cultural reasons, especially among females has been recognised [37].

Despite the adjusted analysis finding that marginal bone loss was significantly greater in cases treated by restorative operators compared to maxillofacial surgeons, the difference of $0.1 \mathrm{~mm}$, is not clinically significant (Tables 5, 6). Maxillofacial surgeons were assigned to more complex cases which could account for a greater risk of problems although it has been shown that more experienced surgeons have higher survival rates [38].

Lemos et al. and Hameed et al. reported that screw retained prostheses had greater crestal bone loss than cement retained, which was found in the present study but the difference was not significant probably because of the low number of cement retained implants at just 66 $[39,40]$.

Furthermore, the present study agrees with Ajanovic et al. [41], who reported that the anterior mandible has the highest crestal bone loss. We report a mean $1.2 \mathrm{~mm}$ of bone loss in the lower anterior region after 1 year of function, which was significantly greater than the other sites mesially but not distally when adjusted for all variables. The anterior part of the mandible is narrow and mainly composed of cortical bone and has less cancellous bone and requires more force to drill, leading to excessive heat generation and crestal bone loss [42].

In the present study, $96.1 \%$ of the implants were still in function with only $3.1 \%$ requiring remake and $0.8 \%$ needed removal. Thus, both the single implant-supported prostheses and the implant-supported fixed prostheses had good survival. This agrees with Pjetursson et al. [43] who estimated the survival rate of implants supporting fixed prostheses was $95.6 \%$ after 5 years and $93.1 \%$ after 10 years. The estimated survival rate after 5 years function in single implant supported crowns was $94.5 \%$ [44], while others estimated the survival rate after 10 years of function in fixed-fixed implant supported prostheses was $86.7 \%$ [1], which is lower than that reported in the present study.

Screw loosening was the most frequent complication $(11.5 \%)$ in this study followed by crown de-cementation (2.7\%). Pjetursson et al. [43] reported that veneering material fracture was the most frequent complication (13.5\%) followed by 5.3\% screw loosening. Because physical properties of veneering ceramic have evolved and improved, chipping is less of a problem nowadays.

The association between complications and gender, age, medical condition and habits is less understood. In this study, implant complications were not significantly different by gender, age, medical condition, smoking, implant manufacturer and operator. Even though there were only 66 cemented cases, implant complications were higher than expected in cement retained prostheses $(70 \%)$ compared to screw retained prostheses (15\%), which is similar to previous findings in so far cement retained prostheses had more biological complications, whereas screw retained had more technical complications [45]. Screw retained prostheses require meticulous surgical technique and prosthetic design whilst cement retained prostheses provide optimal occlusal design, superior aesthetics and passive fit of the restoration [46-48].

A recent systematic review found no statistically significant difference in prosthetic complications among single implant-supported prostheses and implant-supported fixed prostheses [48]. Others have shown that most prosthetic complications among implant-supported fixed prostheses were chipped ceramic $[9,47]$. Most prosthetic complications among single implantsupported prostheses were screw loosening, ceramic chipping and loss of retention $[9,47]$ whilst most technical complications in implant-supported fixed prostheses are fractures of the veneering material, abutment or screw loosening, and loss of retention [44]. The present study found $20 \%$ of implant-supported fixed prostheses had complications which was significantly greater than the $14 \%$ of single implant-supported prostheses. Only 
1\% had chipped ceramic as monolithic Zirconia was used in most cases. Furthermore, the most common prosthetic complication in the present study in both single implant-supported prostheses and implant-supported fixed prostheses was screw loosening which is in line with previous studies. Increased screw loosening has been associated with increased inter-arch distance, increased ratio of crown-to-implant length, inadequate tightening torque and stress generation that changes the screw geometry, causing metal fatigue and ultimately leading to screw loosening $[49,50]$.

The main limitation of the present study is its retrospective design and reliance on the accuracy of patient records. Furthermore, marginal crestal bone loss around implants occurs in a three-dimensional manner whilst the radiographic assessment only allows measurement of the mesial and distal surface but not the buccal and lingual.

\section{Conclusion}

This large-scale study of 1673 implants in 454 subjects found that 3-unit implant-supported prostheses (FDPs) with one intervening pontic had significantly more marginal crestal bone loss compared to single crown supported implants one year after loading. This implies that clinicians should be vigilant and careful periodontal/bone assessment around implant supported FDPs is needed. Implant position and operator were associated with bone loss, but gender, patient's age and medical condition were not. Fixed dental prostheses and their supporting implants had significantly more complications compared to single crowns on implants. Cemented implants had more complications than screw retained.

\section{Abbreviations}

DHA: Dubai Health Authority; D4W: Dental4Windows, Centaur Ltd, Australia.

\section{Acknowledgements}

The authors are very grateful to Dr Hamda Al Mesmar, head of dental services at Dubai Health Authority, for supporting this study.

\section{Authors' contributions}

SAH performed the literature search, collected the data and co-wrote the manuscript. GB conducted advanced statistical analysis. AM co-wrote the manuscript and performed data analysis. All authors read and approved the final manuscript.

\section{Funding}

This study was in partial fulfilment of a Masters program in prosthodontics and was not funded.

\section{Availability of data and materials}

The data that support the findings of this study are available from Dubai Health Authority but restrictions apply to the availability of these data, which were used under license for the current study, and so are not publicly available. Data are however available from the authors upon reasonable request and with permission of Dubai Health Authority.

\section{Declarations}

\section{Ethics approval and consent to participate}

Ethics approval was gained from the Dubai Scientific Research Ethics Committee of the Dubai Health Authority (Reference: DSREC-SR-03/2018_04). No administrative permissions or licenses were required to access patient records as the first author is a DHA employee. All patients gave informed written consent to have treatment in DHA.

\section{Consent for publication}

Not applicable as there are no individual personal data in this study.

\section{Competing interests}

The authors declare that they have no competing interests.

\section{Author details}

${ }^{1}$ Hamdan Bin Mohamed College of Dental Medicine, Mohamed Bin Rashid University of Medicine and Health Sciences (MBRU), Dubai, UAE. ${ }^{2}$ Department of Health Data Science, University of Liverpool, Waterhouse Building Block F, 1-5 Brownlow Street, Liverpool L69 3GL, UK.

Received: 26 October 2019 Accepted: 22 March 2021

Published online: 01 April 2021

\section{References}

1. Pjetursson BE, Brägger U, Lang NP, Zwahlen M. Comparison of survival and complication rates of tooth-supported fixed dental prostheses (FDPs) and implant-supported FDPs and single crowns (SCs). Clin Oral Implants Res. 2007;18(Suppl. 3):97-113.

2. Salinas TJ, Eckert SE. In patients requiring single-tooth replacement, what are the outcomes of implant-as compared to tooth-supported restorations? Int J Oral Maxillofac Implants. 2007;22:71-95.

3. Walton TR. An up-to-15-year comparison of the survival and complication burden of three-unit tooth-supported fixed dental prostheses and implant-supported single crowns. Int J Oral Maxillofac Implants. 2015;30:851-61. https://doi.org/10.11607/jomi.4220.

4. Pol CWP, Raghoebar GM, KerdijkW, Boven GC, Cune MS, Meijer HJA. A systematic review and meta-analysis of 3-unit fixed dental prostheses: Are the results of 2 abutment implants comparable to the results of 2 abutment teeth? J Oral Rehabil. 2018;45(2):147-60.

5. Ravida A, Tattan M, Askar H, Barootchi S, Tavelli L, Wang HL. Comparison of three different types of implant-supported fixed dental prostheses: a long term retrospective study of clinical outcomes and cost-effectiveness. Clin Oral Implants Res. 2019;30(4):295-305.

6. Guichet DL, Yoshinobu D, Caputo AA. Effect of splinting and interproximal tightness on load transfer by implant restorations. J Prosthet Dent. 2002;87(5):528-35.

7. Vigolo P, Mutinelli S, Zaccaria M, Stellini E. Clinical evaluation of marginal bone level change around multiple adjacent implants restored with splinted and nonsplinted restorations: a 10-year randomized controlled trial. Int J Oral Maxillofac Implants. 2015;30(2):411-8.

8. Grossmann Y, Finger IM, Block MS. Indications for splinting implant restorations. J Oral Maxillofac Surg. 2005;63(11):1642-52.

9. Clelland N, Chaudhry J, Rashid RG, McGlumphy E. Split-mouth comparison of splinted and non-splinted prostheses on short implants: 3-year results. Int J Oral Maxillofac Implants. 2016;31(5):1135-41.

10. Clelland N, Seidt JD, Daroz LG, McGlumphy EA. Comparison of strains for splinted and non-splinted implant prostheses using three-dimensional image correlation. Int J Oral Maxillofac Implants. 2010;25(5):953-9.

11. Ting M, Craig J, Balkin BE, Suzuki JB. Peri-implantitis: a comprehensive overview of systematic reviews. J Oral Implantol. 2018;44(3):225-47.

12. Baggi L, Cappelloni I, Di Girolamo M, Maceri F, Vairo G. The influence of implant diameter and length on stress distribution of osseointegrated implants related to crestal bone geometry: a three-dimensional finite element analysis. J Prosthet Dent. 2008;100(6):422-31. 
13. Isidor F. Loss of osseointegration caused by occlusal load of oral implants. A clinical and radiographic study in monkeys. Clin Oral Implants Res. 1996;7(2):143-52.

14. English CE. Biomechanical concerns with fixed partial dentures involving implants. Implant Dent. 1993;2(4):221-42.

15. Korioth TW, Hannam AG. Deformation of the human mandible during simulated tooth clenching. J Dent Res. 1994;73(1):56-66.

16. Hobkirk JA, Schwab J. Mandibular deformation in subjects with osseointegrated implants. Int J Oral Maxillofac Implants. 1991;6(3):319-28.

17. Lindh T, Gunne J, Tillberg A, Molin M. A meta-analysis of implants in partial edentulism. Clin Oral Implants Res. 1998;9(2):80-90.

18. Rokni S, Todescan R, Watson P, et al. An assessment of crown-to-root ratios with short sintered porous-surfaced implants supporting prostheses in partially edentulous patients. Int J Oral Maxillofac Implants. 2005;20(1):69-76.

19. Wittneben JG, Buser D, Salvi G, Burgin W, Hicklin S, Brägger U. Complication and failure rates with implant-supported fixed dental prostheses and single crowns: a 10-year retrospective study. Clin Implant Dent Relat Res. 2014;16(3):356-64.

20. Dubai Annual Health Statistical Report, 2017. https://www.dha.gov.ae. Accessed 2 May 2019.

21. Albrektsson T, Zarb G, Worthington P, Eriksson AR. The long-term efficacy of currently used dental implants: a review and proposed criteria of success. Int J Oral Maxillofac Implants. 1986;1(1):11-25.

22. Norton MR. Multiple single-tooth implant restorations in the posterior jaws: maintenance of marginal bone levels with reference to implantabutment microgap. Int J Oral Maxillofac Implants. 2006;21(5):777-84.

23. Mendonca J, Francischone C, Senna P, Matos de Olivra A, Sotto-Maior B. A retrospective evaluation of the survival rates of splinted and non-splinted short dental implants in posterior partially edentulous jaws. J Periodontol. 2014;85(6):787-94.

24. Ferrario VF, Sforza C, Serrao G, Dellavia C, Tartagilia GM. Single tooth bite forces in healthy young adults. J Oral Rehabil. 2004;31:18-22.

25. Takaki P, Vieira M, Bommarito S. Maximum bite force analysis in different age groups. Int Arch Otorhinolaryngol. 2014;18(3):272-6.

26. Vissink A, Spijkervet FKL, Raghoebar GM. The medically compromised patient: Are dental implants a feasible option? Oral Dis. 2018;24:253-60

27. Alqutaibi AY, Radi IA. No clear evidence regarding the effect of osteoporosis on dental implant failure. J Evid Based Dent Pract. 2016;16(2):124-6.

28. Temmerman A, Rasmusson L, Kübler A, Thor A, Quirynen M. A prospective, controlled, multicenter study to evaluate the clinical outcome of implant treatment in women with osteoporosis/osteopenia: 5-year results. J Dent Res. 2019;98(1):84-90.

29. Naujokat H, Kunzendorf B, Wiltfang J. Dental implants and diabetes mellitus - a systematic review. Int J Implant Dent. 2016;2(1):1-10.

30. Diz P, Scully C, Sanz M. Dental implants in the medically compromised patient. J Dent. 2013;41(3):195-206.

31. Kim SY, Dodson TB, Do DT, Wadhwa G, Chuang S-K. Factors associated with crestal bone loss following dental implant placement in a longitudinal follow-up study. J Oral Implantol. 2015;41(5):579-85.

32. Guo S, DiPietro LA. Factors affecting wound healing. J Dent Res. 2010;89(3):219-29.

33. Pedro RE, De Carli JP, Linden MS, Lima IF, Paranhos LR, Costa MD, Bós ÂJ. Influence of age on factors associated with peri-implant bone loss after prosthetic rehabilitation over osseointegrated implants. J Contemp Dent Pract. 2017;18(1):3-10

34. Calvo-Guirado JL, Lopez-Lopez PJ, Perez-Albacete Martınez C, Javed F, Granero-Marın JM, Mate Sanchez de Val JE, Ramırez Fernandez MP. Peri-implant bone loss clinical and radiographic evaluation around rough neck and microthread implants: a 5-year study. Clin Oral Implants Res. 2018;29:635-43.

35. Jradi H, Wewers ME, Pirie PP, Binkley PF, Ferketich AK. Cigarette and waterpipe smoking associated knowledge and behaviour among medical students in Lebanon. East Mediterr Health J. 2013;19(10):861-8.

36. Ansari K, Farooqi FA. Comparison and prevalence of smoking among Saudi females from different Departments of the College of Applied Medical Sciences in Dammam. Int J Health Sci. 2017;11(5):56-62.

37. Al-Houqani M, Leinberger-Jabari A, Al Naeemi A, Al Junaibi A, Al Zaabi EA, Oumeziane N, et al. Patterns of tobacco use in the United Arab Emirates Healthy Future (UAEHFS) pilot study. PLoS ONE. 2018;13(5):e0198119.

38. Chrcanovic BR, Alberktsoon T. Impact of different surgeons on dental implant failure. Int J Prosthodont. 2017;30:445-54.

39. Lemos CA, de Souza Batista VE, Almeida DA, Santiago Junior JF, Verri FR, Pellizzer EP. Evaluation of cement-retained versus screw-retained implantsupported restorations for marginal bone loss: a systematic review and meta-analysis. J Prosthet Dent. 2016;115:419-27.

40. Hameed MH, Khan FR, Ghafoor R, Azam SI. Marginal bone loss around cement and screw-retained fixed implant prosthesis. J Clin Exp Dent. 2018;10(10):949-54.

41. Ajanović M, Hamzić A, Redžepagić S, Kamber-Ćesir A, Kazazić L, Tosum S. Radiographic evaluation of crestal bone loss around dental implants in maxilla and mandible: One year prospective clinical study. Acta Stomatol Croat. 2015;49(2):128-36.

42. Eriksson RA, Albrektsson T. The effect of heat on bone regeneration: an experimental study in the rabbit using the bone growth chamber. J Oral Maxillofac Surg. 1984;42(11):705-11.

43. Pjetursson BE, Thoma D, Jung R, Zwahlen M, Zembic A. A systematic review of the survival and complication rates of implant supported fixed dental prostheses (FDPs) after a mean observation period of at least 5 years. Clin Oral Implants Res. 2012;23(6):22-38.

44. Sailer I, Mühlemann S, Zwahlen M, Hämmerle CH, Schneider D. Cemented and screw-retained implant reconstructions: a systematic review of the survival and complication rates. Clin Oral Implants Res. 2012;23(6):163-201.

45. Michalakis KX, Hirayama H, Garefis PD. Cement-retained versus screwretained implant restorations: a critical review. Int J Oral Maxillofac Implants. 2003;18(5):719-28.

46. Hebel KS, Gajjar RC. Cement-retained versus screw-retained implant restorations: achieving optimal occlusion and esthetics in implant dentistry. J Prosthet Dent. 1997;77:28-35.

47. Freitas AC, Bonfante EA, Rocha EP, Silva NR, Marotta L, Coelho PG. Effect of implant connection and restoration design (screwed vs. cemented) in reliability and failure modes of anterior crowns. Eur J Oral Sci. 2011;119:323-30

48. Batista V, Verri F, Lemos C, Cruz R, Oliveira H, Gomes J, Pellizzer E. Should the restoration of adjacent implants be splinted or nonsplinted? A systematic review and meta-analysis. J Prosthet Dent. 2019;121:41-51.

49. Sivolella S, Stellini E, Testori T, Di Fiore A, Berengo M, Lops D. Splinted and unsplinted short implants in mandibles: a retrospective evaluation with 5 to 16 years of follow-up. J Periodontol. 2013;84:502-12.

50. Kim ES, Shin SY. Influence of the implant abutment types and the dynamic loading on initial screw loosening. J Adv Prosthodont. 2013;5:21-8.

\section{Publisher's Note}

Springer Nature remains neutral with regard to jurisdictional claims in published maps and institutional affiliations. 